\title{
Estrogen receptor coregulators and pioneer factors: the orchestrators of mammary gland cell fate and development
}

\author{
Bramanandam Manavathi *, Venkata S. K. Samanthapudi and Vijay Narasimha Reddy Gajulapalli
}

Department of Biochemistry, School of Life Sciences, University of Hyderabad, Hyderabad, India

\section{Edited by:}

Claude Beaudoin, Blaise Pascal University Clermont-Ferrand 2,

France

Reviewed by:

Anne Hélène Duittoz, Université de

Tours, France

Songhai Chen, University of lowa,

USA

\section{*Correspondence:}

Bramanandam Manavathi, Department of Biochemistry, School of Life Sciences, University of Hyderabad, Gachibowli,

Hyderabad-500046, India

e-mail:manavathibs/@uohyd.ernet.in
The steroid hormone, 17ß-estradiol (E2), plays critical role in various cellular processes such as cell proliferation, differentiation, migration and apoptosis, and is essential for reproduction and mammary gland development. E2 actions are mediated by two classical nuclear hormone receptors, estrogen receptor $\alpha$ and $\beta$ (ERs). The activity of ERs depends on the coordinated activity of ligand binding, post-translational modifications (PTMs), and importantly the interaction with their partner proteins called "coregulators." Because coregulators are proved to be crucial for ER transcriptional activity, and majority of breast cancers are ER $\alpha$ positive, an increased interest in the field has led to the identification of a large number of coregulators. In the last decade, gene knockout studies using mouse models provided impetus to our further understanding of the role of these coregulators in mammary gland development. Several coregulators appear to be critical for terminal end bud (TEB) formation, ductal branching and alveologenesis during mammary gland development. The emerging studies support that, coregulators along with the other ER partner proteins called "pioneer factors" together contribute significantly to E2 signaling and mammary cell fate. This review discusses emerging themes in coregulator and pioneer factor mediated action on ER functions, in particular their role in mammary gland cell fate and development.

Keywords: estrogen, estrogen receptor, coregulators, pioneer factors, mammary gland development

\section{INTRODUCTION}

Mammary gland development occurs postnatally unlike other human organs (Russo and Russo, 2004). The ovarian hormones, $17 \beta$-estradiol (hereafter referred to as E2) and progesterone play a pivotal role in mammary gland development. Although prenatal development of mammary gland is relatively independent of these steroid hormones, pronounced growth occurs during puberty which requires E2. Hence, the hormone-dependent mammary gland development occurs only after puberty. The ovarian hormones impact profound morphogenetic changes in the development of gland by inducing ductal elongation, side branching, terminal end bud (TEB) formation and alveologenesis (Brisken and O'malley, 2010).

E2 exerts its biological functions through specific ligandinducible nuclear receptors, namely estrogen receptors (ERs) $\mathrm{ER} \alpha$ and ER $\beta$. These receptors are encoded by genes located on two different chromosomes and share considerable sequence homology (Nilsson et al., 2001). These proteins regulate the transcription of a diverse array of target genes during development and, in response to specific physiological and pathological signals (Klinge, 2000). Knockout mouse studies have clearly demonstrated that ER $\alpha$ is indispensible for the postnatal development of mammary gland while ER $\beta$ is not (Mueller et al., 2002; Mallepell

Abbreviations: TEBs, terminal end buds; KO, knockout; Tg mice, transgenic mice; $\mathrm{ER} \alpha$, estrogen receptor alpha; Esrl, estrogen receptor alpha gene 1; SHR, steroid hormone receptor; PTMs, post-translational modifications; PgR, progesterone receptor; MaSC, mammary stem cells. et al., 2006; Feng et al., 2007). The canonical action of the ER involves binding to its ligand with a concomitant dissociation from HSP chaperone proteins, receptor dimerization, nuclear entry and binding to E2 response elements (EREs) located within the promoter/enhancer regions of the target genes to regulate transcription (Klein-Hitpass et al., 1988; Echeverria and Picard, 2010). Accumulating evidence suggests that ER $\alpha$ is preferentially recruited at enhancer regions of target genes upon E2 stimulation (Carroll et al., 2005; Welboren et al., 2009; Gertz et al., 2012; Ross-Innes et al., 2012; Xiao et al., 2012). These enhancer elements modulate target gene expression by forming chromatin loops (Lieberman-Aiden et al., 2009; Sanyal et al., 2012). This is strengthened by the fact that ER $\alpha$ depletion leads to transcriptional repression and loss of chromatin loops, thereby supporting the notion that ER $\alpha$ indeed participates in chromatin loop formation in the breast cancer cells (Fullwood et al., 2009).

In contrast, a recent study suggests that unliganded $\mathrm{ER} \alpha$ also binds to large number of chromatin sites in breast cancer cells and, this binding is specifically linked to genes with developmental functions (Caizzi et al., 2014). ER $\alpha$ can also affect gene transcription indirectly through its physical interaction with other transcription factors, such as activator protein 1 (AP1), SP1,

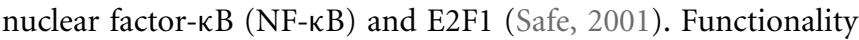
of the ER $\alpha$ is further regulated by the post-translational modifications (PTMs) and its cooperative interaction with a special category of proteins called "coregulators," which exhibit with a coactivator or corepressor activities (Lonard and O'malley, 
2007). The importance of coregulators in ER functions as demonstrated in vitro generated intense research to decipher their role in mammary gland development. In vivo characterization of several coregulators of $\mathrm{ER} \alpha$ provides further impetus to their biological roles in normal and pathological conditions.

\section{THE CONCEPT OF "COREGULATOR"}

The concept of coregulator was introduced to the field of nuclear receptors approximately two decades ago (Onate et al., 1995). Though there was confusion initially about classifying these molecules as cofactors based on their similarity to a cofactor of an enzyme, they were later referred as "coregulators" (O'malley and Mckenna, 2008). Unlike the function of a cofactor to an enzyme, coregulator acts as a bridging or helper molecule that helps in forming large protein complexes to modulate appropriate activity on target gene chromatin. Although enzymes exhibit absolute cofactor specificity in a tissue-independent manner, steroid hormone receptors (SHRs) utilizes different tissue-specific coregulators for their activity in a spatio-temporal manner. SHRs being transcription factors, the coregulators may positively or negatively influence the receptor's transcriptional activity by modifying the target gene chromatin. The coregulators that enhance the transcriptional activity of SHRs are called coactivators, and those that decrease it are called corepressors. Though, coregulators form large protein complexes with SHRs, they are just not "bridging" molecules that link SHR and the transcription machinery rather, they often exhibit various enzymatic activities for example, acetylation, methylation, and ubiquitination, that are required for the appropriate regulation of the target gene transcription (Lonard and O'malley, 2007). In general, coactivators contain an intrinsic histone acetyl transferase (HATs) activity. Alternatively they may recruit HATs to the target gene chromatin along with SHRs to enhance the transcriptional activity of the receptor. In contrast, corepressors recruit histone deacetylases (HDACs) to the target gene chromatin to keep the chromatin in closed conformation thus shutting off the target gene transcription (Figure 1). The global actions of coregulators involve chromatin modification and remodeling, initiation of transcription, elongation of RNA chains, mRNA splicing, mRNA translation, miRNA processing, and interestingly degradation of the activated NR-coregulator complexes and termination of the transcriptional response (Lonard and O'malley, 2007). In vivo studies using knockout mouse models provided evidence that several of these coregulators are important for E2-dependent mammary growth and the same are discussed here.

\section{ER COREGULATORS, THE ORCHESTRATORS OF E2 SIGNALING}

Because majority of breast cancers are $\operatorname{ER} \alpha$ positive and coregulators proved to be crucial for ER transcriptional activity, an increased interest in the field has led to the identification of a large number of coregulators (Lonard and O'malley, 2006). Deregulated expression of large number of coregulators is associated with breast cancer development (Manavathi et al., 2013). The first discovered coregulator of $\mathrm{ER} \alpha$ is SRC-3/AIB1 (Onate et al., 1995). So far large number of coregulators have been

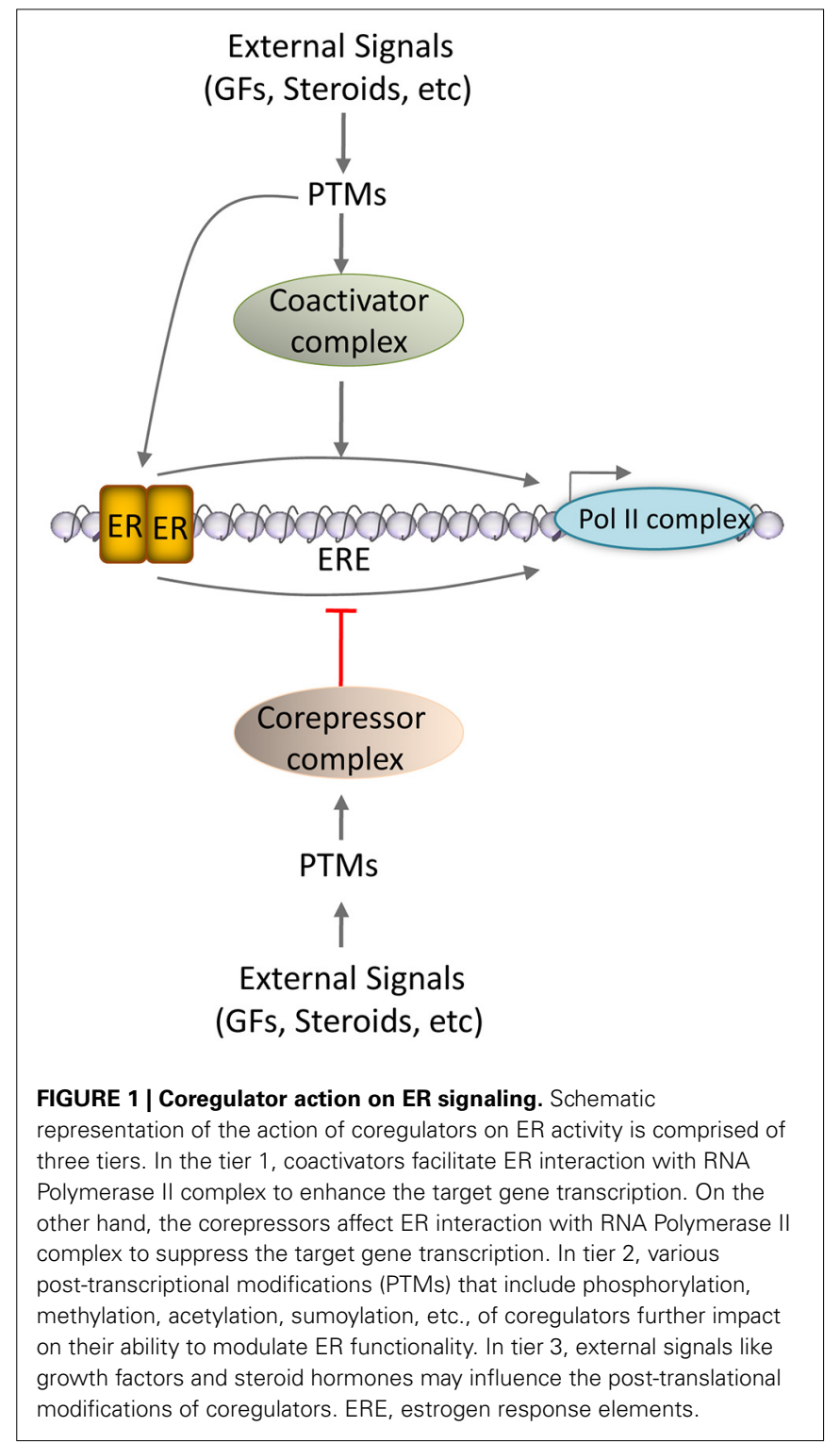

identified for $\mathrm{ER} \alpha$, whereas very few coregulators are known for ER $\beta$ (Lonard and O'malley, 2006). Though ER $\alpha$ and ER $\beta$ utilize E2 as their physiological ligand, they have overlapping and distinct functions. This could be partly explained by their differential utilization of coregulators. The different classes of ER $\alpha$ (hereafter we referred as ER) coactivators include members of steroid receptor coactivator (SRC)/p160 family, the histone acetyltransferase cAMP responsive element binding protein (CREB)-binding protein $(\mathrm{CBP}) / \mathrm{p} 300$, ATP-dependent chromatin remodeling complexes like SWI/SNF, E3 ubiquitin-protein ligases and steroid RNA activator (SRA) (Lonard and O'malley, 2006). Majority of coactivators utilize specific motifs called NR boxes or LXXLL motifs (X, any amino acid; L, Leucine) to mediate their interaction with ligand-binding domains of ER (Heery et al., 1997). Conversely, corepressors inhibit ER-mediated gene transcription through a direct interaction with unliganded ER or by utilizing corepressor nuclear receptor (CoRNR) box present in it or 
by competing with coactivators for ER binding ( $\mathrm{Hu}$ and Lazar, 1999).

The intriguing question about the ER field is the presence of many coregulators for ER $(>200)$. It is reported that differential expression of coregulators in many tissues account for cell-specific regulation of E2 target gene expression (Misiti et al., 1998; Smith and O'malley, 2004). This implies that the degree of coregulator expression is critical to their ability to influence the transcriptional potential of the ERs that allows fine-tuning of target gene transcription in response to E2 (Brisken and O'malley, 2010). Interestingly, the concentration of several coregulators of ER is subjected to transcriptional regulation by E2, and in turn these coregulators regulate the expression of ERs, thus operating feedback mechanisms that are common in endocrine regulation (Mishra et al., 2004). Various PTMs such as phosphorylation, methylation, ubiquitination, SUMOylation and acetylation also influence the activity of coregulators and, thereby target gene expression (Lonard and O'malley, 2007; O'malley et al., 2008; Han et al., 2009) (Figure 1). Combined or individual modifications on a coregulator can bestow distinct activities for the same coregulator. In this way, a repertoire of coregulators is generated in a cell so that these regulatory molecules are used at appropriate time and conditions.

\section{ROLE OF ER COREGULATORS IN MAMMARY GLAND DEVELOPMENT}

Although the role of E2 in mammary gland development is well established through endocrine disruption procedures, the precise role of its cognate receptor ER in mammary gland development is derived from mouse knockout studies. Disruption of Esr1 (ER) gene in mouse led to complete abrogation of the mammary gland development indicating that ER is indispensible for the mammary gland development (Mueller et al., 2002; Mallepell et al., 2006; Feng et al., 2007). Because ER-mediated activity depends critically on its coregulator proteins, they are expected to play crucial role in mammary gland development. Knockout approaches were employed to address the role of coregulators in mammary development. Distinct phenotypes such as embryonic lethality, metabolic diseases, impaired reproduction and defects in mammary gland development were evident upon complete ablation of several ER coregulators (Lonard et al., 2007; Dasgupta et al., 2014). The role of various coregulators in mammary gland development is summarized in Figure 2. Mammary gland-specific conditional knockouts are required for understanding the role of coregulators whose complete deletion in mouse results in embryonic lethality. This helps to understand whether they indeed participate in mammary gland development or not. In this review, we will restrict our discussion to the findings till now that connect coregulators to mammary gland development.

\section{AIB/SRC FAMILY}

The well characterized amplified in breast cancer (AIB)/steroid receptor coregulator (SRC)/p160 family of coactivators appeared to be involved in regulating uterine growth, embryo implantation, fertility and mammary gland development (Xu et al., 1998, 2000; Gehin et al., 2002; Nishihara et al., 2003). The three SRC's, SRC-1, 2, and 3, have been shown to coactivate ER signaling in mammary epithelial and cancer cells. SRC coactivators contain LXXLL motif which helps them to interact with AF-2 domain of ER and, possesses an intrinsic histone acetyltransferase activity (Mcinerney et al., 1998). The typical mechanism of action by these coregulators includes recruitment of secondary coactivators such as p300, cAMP response element binding protein-binding protein and coactivator-associated arginine methyltransferase 1, which exhibits histone methyltransferase activity, on the target gene promoters to enhance the ER-mediated transcription via chromatin modification (Chen et al., 1999, 2000).

In vivo studies established that SRC-1 is required for normal mammary ductal elongation and alveolar development (Xu et al., 1998). Knockout (KO) mouse of Src-1 had normal body size but showed decreased mammary ductal branching and alveologenesis. Further, Src-1 KO mice displayed moderate motor dysfunction, delayed development of Purkinje cells, control of energy balance, loss of skeletal response to E2, altered hypothalamicpituitary-adrenal axis function and hepatic malfunction (Xu et al., 1998; Nishihara et al., 2003). The specific effects on mammary gland in Src-1 KO mice are that the extent of ductal branching as well as the number of branches was substantially reduced in the mammary glands, spreading of ductal is only half the area of the mammary fat pad and the alveoli that are much less developed in terms of number and size, though milk production is normal. It implies that Src-1 is an important coregulator of ER for ductal branching at puberty and is required for alveologenesis during pregnancy.

Similar to $S r c-1$ KO mice, the disruption of Src-2 (GRIP-1 or TIF2) led to severe abnormalities in reproductive function (Gehin et al., 2002). Surprisingly, mammary glands from virgin, pregnant and nursing Src2 null females were histologically and functionally normal suggesting that $S r c-2$ is not required for early postnatal development of the mammary gland. Interestingly, SRC-2 protein is expressed in mammary epithelial cells that are positive for progesterone receptor (PgR) indicating that mammary $\mathrm{Src}-2$ may occupy a crucial role in progesterone-mediated proliferative developments (Mukherjee et al., 2006). Accordingly, Src-2 KO mice epithelium do not undergo proliferation even in the presence of mammary PgR clearly implying that Src-2 is indispensable in progesterone-induced mammary ductal side branching and alveologenesis but not for E2 regulated ductal development. Thus, SRC-2 does not integrate into ER signaling in vivo directly but could be through PgR signaling.

Similar to the other SRCs, SRC-3 (AIB1, ACTR, and TRAM-1) is also critical for mammary gland development. Src-3 KO mice display retarded mammary gland development, dwarfism, delayed puberty and reduced female reproductive function (Xu et al., 2000). Tissue expression analysis suggested that Src-3 is highly expressed in the TEBs and epithelial cells of mammary gland. Despite its expression in TEBs, Src-3 is not required for TEBs growth. It seems that the retardation of mammary ductal growth in the $S r c-3$ null mice is due to low levels of E2 (Xu et al., 2000). Therefore, E2 therapy successfully rescued the growth deficiency of mammary ducts suggesting that Src3 is not essential for the E2-stimulated ductal growth in virgin mice despite of its high expression in mammary gland epithelial cells. But during alveolar development, $S r c-3$ is required for 


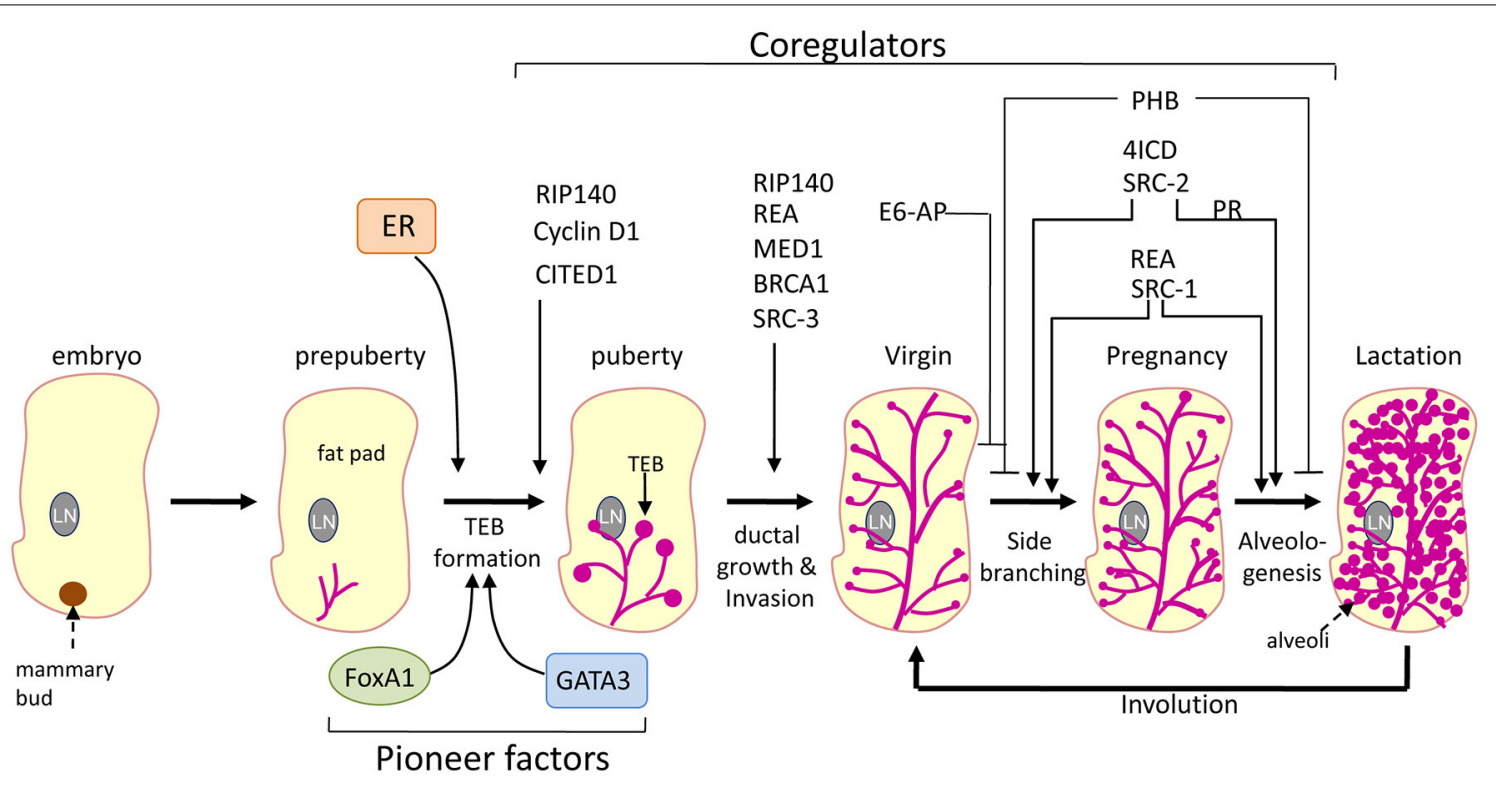

FIGURE 2 | Role of coregulators and pioneer factors in mammary gland development. Schematic representation of the role of various coregulators and pioneer factors of ER on different stages of mammary gland

development. The thin arrows points to the developmental defects at these stages of mammary gland development due to the loss of the expression of respective coregulator. Whereas the inhibitory lines (-|) points to the suppressive effect of the respective coregulator at the indicated stages of mammary gland development. LN, lymph node; TEB, terminal end buds. progesterone-stimulated cell proliferation and glandular differentiation (Xu et al., 2000). The comparative summary indicates that the physiological role of SRCs is different from one another and proves the diversity among coactivator family members.

\section{BRCA1}

Breast cancer associated protein 1 (BRCA1), a tumor suppressor, was initially identified as a gene predisposed to breast and ovarian cancers (Miki et al., 1994). Rosen group identified BRCA1 as a transcriptional inhibitor of ER (Fan et al., 1999), bringing the first link between ER and BRCA1. BRCA1 inhibits ER transcriptional activity through direct interaction between the BRCA1 and ER proteins and partly, by regulating the expression of $\mathrm{p} 300$, a transcriptional coactivator for ER (Fan et al., 2001, 2002). The N-terminal region of BRCA1 interacts with AF-2 domain of $\mathrm{ER}$, while the carboxyl-terminus mediates the repressor function. For instance, BRCA1 inhibits E2-inducible secretion of vascular endothelial growth factor (VEGF) (Zheng et al., 2001; Kawai et al., 2002). Mechanistic studies indicate that BRCA-mediated inhibition of ER transcriptional activity relies on the ability of BRCA1 to mono-ubiquitinate ER which in turn is dependent on the acetylation status of ER (Eakin et al., 2007). Interestingly, BRCA1 is upregulated in response to E2 in mammary epithelial cells and, BRCA1 in turn transcriptionally regulates ER positively by associating with OCT-1, a transcription factor. This implies the existence of a positive feedback mechanism that regulates functional interaction between ER and BRCA1 in breast cancer cells (Spillman and Bowcock, 1996). BRCA1 regulates ER expression positively, hence loss of BRCA1 can lead to ER-negative phenotype providing a molecular basis for the loss of ER expression in the majority of BRCA1 mutant cancers (Hosey et al., 2007).
The physiological link between BRCA1 and mammary gland development was established using knockout mouse models. Brcal deletion in mice using tissue-specific conditional knockouts resulted in impaired mammary development (Xu et al., 1999). The $\mathrm{BrCa1}^{-/-}$mammary glands are smaller due to increased cellular apoptosis and, they also display abnormal ductal morphogenesis. Initial studies suggested an important developmental role for the murine homolog of BRCA1 in the regulation of cell proliferation and differentiation. In consistent with these results, in vitro studies using the HC11 murine mammary epithelial cell line showed that Brcal mRNA and protein levels increased during lactogenic differentiation (Rajan et al., 1997). Loss of BRCA1 results in impaired differentiation while increased proliferation of MCF10A (a human mammary epithelial cell line), further suggesting its strong association with cellular differentiation. These cellular differentiation functions are probably due to the fact that BRCA1 transcriptionally regulates a number of basal and luminal terminal differentiation markers that define a cell fate within the mammary gland (Hosey et al., 2007; Gorski et al., 2009). Recent studies show that BRCA1 indeed promotes differentiation along the luminal lineage in coordination with Notch signaling (Buckley et al., 2011). Furthermore, BRCA1 is also shown to collaborate with GATA3 to regulate genes crucial for the maintenance of luminal lineage (Kouros-Mehr et al., 2006; Tkocz et al., 2012). It thus implies that BRCA1 is required for luminal cell differentiation during mammary gland development.

\section{CITED-1}

CITED-1, a CBP/p300-binding nuclear protein, functions as a selective coactivator for E2-dependent transcription. In ERpositive breast cancer cells, CITED-1 binds directly to ER through its transactivation domain and sensitizes the cells to E2 by 
stabilizing the E2-dependent interaction between p300 and ER (Yahata et al., 2001). CITED-1 coactivator function is genespecific as it doesn't induce ER signature genes such as progesterone receptor, $P g R$ or $p S 2$, rather it upregulates TGF- $\beta$ in MCF-7 cells (Yahata et al., 2001). Thus the induced TGF- $\beta$ in turn modulates the proliferative action of E2 (Ewan et al., 2002).

Gene profiling analysis in different regions of mammary ductal tree identified CITED-1 as one of the selectively expressed genes in a subset of luminal and preluminal epithelial cells in the pubertal mammary gland (Howlin et al., 2006). This led to the possibility that CITED-1 may mediate signals in the E2-TGF- $\beta$ regulatory axis. During puberty, CITED-1 localizes to the luminal epithelial cell population of the mammary ducts and the body cells of the TEBs. Characterization of Cited $1 \mathrm{KO}$ mice revealed that Cited 1 is required for ductal growth during puberty as homozygous null mutant's exhibited retarded mammary ductal growth. The other prominent Cited-1 KO's mammary phenotype was altered ductal morphology with dilated and spatially restricted branches (Howlin et al., 2006). These defects in mammary glands of Cited $-1 \mathrm{KO}$ are attributed to alterations in the transcription of a number of key downstream targets of both E2 and TGF- $\beta$. Further, loss of EGFR/ErbB2 ligand (amphiregulin) expression, one of the prime targets of E2, was observed in Cited-1 null mice. It thus implies the potential maintenance of the ER-CITED-1 co-regulated signaling pathway in the pubertal mammary gland.

\section{CYCLIN D1}

Cyclin D1, encoded by $C c d n 1$ gene which is located on chromosome 11q13, forms the regulatory subunit of cyclin-dependent kinases 4 (CDK4) and, was found to be overexpressed in 50\% of breast cancers (Ormandy et al., 2003). It is shown to coactivate ER-dependent transcription in a ligand-independent manner (Zwijsen et al., 1998; Lamb et al., 2000). Cyclin D1 competes with BRCA1, which represses ER transactivation, for binding to hinge region of ER thereby it display coactivator function (Wang et al., 2005). In contrast, genome-wide expression profiling in Cond1 KO mice treated with E2 demonstrated that cyclin D1 determines large number of E2-responsive genes in vivo (Casimiro et al., 2013). Further, in cyclin D1-silenced (by RNAi) MCF7 cells, it was evident that cyclin D1 is required for E2mediated gene expression in vitro. These results are further substantiated by genome-wide chromatin immunoprecipitationsequencing (ChIP-Seq) analysis. It was observed that cyclin D1 indeed binds to the E2-ER target gene chromatins, ErbB3, EphB3, and their ligands, amphiregulin and matrix metalloproteinase. The above facts suggest that cyclin D1 mediates E2-dependent ER transactivation and is required for convergence of ER and growth factor signaling at a common cis-element of growth factor genes.

Though deletion of $C c d n 1$ in mice is not lethal, $C c d n 1$ ablation results in the arrest of mammary gland development before lobuloalveolar development, thereby underscoring its definitive role in this process (Fantl et al., 1999). The defects in the mammary gland are due to loss of expression of several E2- and cyclin D1-depenndent genes. In $C c d n 1 \mathrm{KO}$ pregnant mice, the glands do not open due to lack of lobuloalveolar growth. The epithelial cell-specific overexpression of $C c d n 1$ in mice leads to mammary carcinoma indicating that the optimal concentration of $C c d n 1$ is required for proper development of mammary gland (Wang et al., 1994). This could partly explain why cyclin D1 overexpression is associated with $50 \%$ of breast cancers.

\section{E6-AP}

E6-associated protein (E6-AP) is a HECT (homologous to E6associated protein carboxy-terminal) domain containing E3 ubiquitin ligase that is known to act as a coactivator for ER, PR and RXR $\alpha$ (Nawaz et al., 1999). E6-AP possesses two independent discrete functions: coactivation of ER and ubiquitin-protein ligase activity (Ramamoorthy and Nawaz, 2008). Being a component of the ubiquitin-proteasome pathway, it was presumed that E6-AP may regulate the dynamics of steroid hormone receptormediated transcription by modulating the degradation of the transcriptional complexes. However, this still remains elusive as ER stability is known to correlate with E6-AP expression (Gao et al., 2005). Down regulation of E6-AP leads to increased ER levels. On the other hand, E6-AP enhances the transcriptional activity of ER by recruiting chromatin modifiers like p300 at ER target gene promoters (Catoe and Nawaz, 2011). Furthermore, phosphorylation of ER at tyrosine 537 (Y537) by Src kinase is shown to potentiate ER binding to the ubiquitin E6-AP, subsequent ER ubiquitination, target gene activation and ultimately loss of ER function (Sun et al., 2012). This also suggests that a delicate balance between coactivator function and degradation activity of E6-AP, which attributes to its role in mammogenesis as well as breast cancer development.

E6-ap $\mathrm{KO}$ mice display reduced gonadal size suggesting its role in fertility. Though E6-AP is expressed in mammary gland, E2 and progesterone-stimulated growth of virgin mammary gland was not compromised by E6-ap ablation, suggesting that E6-AP is not important in mediating steroid hormone actions in vivo (Smith et al., 2002). In another study, it was shown that overexpression of E6-AP (WT) results in impaired mammary gland development. Overexpression of defective E6-AP (C833S) (an ubiquitin ligase-defective), or the loss of E6-ap increased lateral branching and alveolus-like protuberances in the mammary gland. The mammary phenotypes observed in the E6-AP transgenic are attributed to the alteration in the level of progesterone receptor-B (Pgr-B), an ER target gene (Ramamoorthy et al., 2012). These studies indicate that E6-AP inhibits lateral branching during mammary gland development.

\section{HER4/4ICD}

The HER4/ErbB4 is an EGFR family member that is proteolytically processed at the cell surface to release the cytosolic side fragment i.e., intracellular domain (4ICD), which independently impacts a variety of functions including acting as a coactivator for ER (Naresh et al., 2006; Zhu et al., 2006). Its functions are found to be location specific. For example, nuclear 4ICD in tumor cells acts as a potent ER coactivator leading to E2-stimulated proliferation of breast cancer cells, whereas in mammary gland, it regulates differentiation and lactation via STAT5 pathway (Williams et al., 2004). Cytosolic 4ICD accumulates in mitochondria where it regulates apoptosis (Naresh et al., 2006; Zhu et al., 2006). Endogenous 4ICD interacts with and potentiates ER 
transactivation in breast cancer cells as loss of 4ICD expression decreases ER-mediated transactivation function, whereas overexpression of 4ICD in the MCF-7 cell line increased E2 stimulation of ERE reporter activity (Zhu et al., 2006). Interestingly, the E2 stimulation of ER drives nuclear translocation of 4ICD. The nuclear localized ER/4ICD complex then selectively is recruited to E2-inducible gene promoters. The 4ICD displays gene-specific coactivation functions toward ER as it coactivates transcription of progesterone receptor $(\mathrm{PgR})$ and stromal cell-derived factor 1 (SDF-1) but not trefoil factor 1 precursor (pS2) (Zhu et al., 2006). Although substantial evidence supports that 4ICD functions as a transcriptional coactivator, the precise mechanism of action toward ER is not known. Interestingly, Her4 itself is an E2inducible gene and, ER/4ICD complex recruits to Her4 promoter in response to E2. Because, Her4 expression is also shown to be required for the growth-promoting action of E2 in breast cancer cells, it provides evidence for the involvement of an autocrine signaling in breast cancer cells. This suggests that 4ICD is a unique coregulator of ER that directly couples extranuclear and nuclear E2 actions in breast cancer cells (Zhu et al., 2006).

The in vivo role of 4ICD on ER functions is assessed using knockout mice without Her4 which is the mature form of 4ICD. Her-4 KO in mice causes embryonic lethality at day 11 due to defects in heart development (Tidcombe et al., 2003). The rescued Her4 mutant mice are viable and fertile, but they do not lactate, indicating the role of Her-4 in mammary gland development. Progesterone receptor (PgR) is known to be required for lobuloalveolar development in mammary gland and, E2 regulates expression of $P g r-A$, whereas expression of $P g r-B$ is E2 independent (Tanos et al., 2012). Consistent with a role for 4ICD in E2-regulated $P g R$ expression in vitro, $P g R-A$, but not $P g R$ $B$, expression was abolished in mammary glands of Her4-null mouse. The study by Risicki et al., provided further evidence that 4ICD is nuclear localized in mammary epithelium and acts as coactivator in the mammary development (Rokicki et al., 2010). In summary, 4ICD is a physiologically important ER coactivator and it cooperates with ER to potentiate Pgr expression in the normal breast.

\section{MED1}

MED1, also known as DRP205/TRAP220/PBP, is one of the coactivators of a large $~ 1.6 \mathrm{MDa}$ protein complex called "Mediator," which is a part of the RNA polymerase II holoenzyme. "Mediator" bridges the communication between transcriptional activators and RNA polymerase II to influence the transcription (Malik et al., 2004). Therefore, MED1 has been shown to act as a coactivator for ER. The LXXLL motifs of MED1 are crucial for its interactions with nuclear receptors and for nuclear receptor-mediated transcription of target genes (Jiang et al., 2010).

To understand its functional significance in steroid hormone receptor action and mammary gland development, Med1 LXXLL motif-mutant knockin (KI) mice $\left(\mathrm{Med} 1^{K I / K I}\right)$ were generated since complete deletion of Med1 leads to embryonic lethality. Med $1^{K I / K I}$ mice were fertile and normal but exhibited profound abnormalities at the virgin stage indicating defects in pubertal mammary gland development (Jiang et al., 2010). The defects observed in mammary gland development in $\mathrm{Med} 1^{\mathrm{KI} / \mathrm{KI}}$ mice are attributed to significant impairments both in ER-dependent gene expression in mammary epithelial cells and in E2-stimulated mammary ductal growth further indicating the significance of LXXLL motifs in coactivator function. Because Med1 gene ablation in mice led to embryonic lethality, a recent study conducted on the Med1/Med24 double heterozygous $\mathrm{KO}$ (dhKO) mice, which are viable, addressed the role of Med1 in mammary gland development (Hasegawa et al., 2012). Mammary glands from Med1/Med24 dhKO mice showed profound impediment in ductal branching during puberty, while in single haplo-insufficient mice, glands developed normally. These phenotypic differences point out to the possibility that other subunits of "Mediator" complex are engaged. Further, DNA synthesis of both luminal and basal cells were impaired in double mutant mice. The expression of ER-dependent genes such as E2F1 and cyclin D1, which promote progression through the $\mathrm{G}(1) / \mathrm{S}$ phase of the cell cycle, was attenuated. These studies established the coactivator functions of "Mediator" complex for ER in normal mammary epithelial cells.

\section{MTA1 FAMILY}

The metastasis-associated proteins are a small family of coregulators which comprises of MTA1, MTA2, MTA3, and MTA1s. Individual MTAs takes part as critical components of nuclear remodeling and deacetylation (NuRD) complex, and therefore represses target gene expression through deacetylation of histones in the chromatin (Manavathi and Kumar, 2007). The first target gene identified for MTA1/NuRD complex is ER and the ligand-dependent transactivation functions of ER are repressed in cultured breast cancer cells (Mazumdar et al., 2001). The Mta1 $\mathrm{KO}$ mice are viable but the information about the mammary gland development in these mice is obscure (Manavathi et al., 2007). Mice overexpressing MTA1 (MTA1-Tg) under the control of the mouse mammary tumor virus (MMTV) promoter long terminal repeat was used to understand its role in mammary gland. Extensive side branching and precocious differentiation due to increased proliferation of ductal and alveolar epithelial cells was observed in mammary glands of MTA1-Tg virgin mice (BagheriYarmand et al., 2004). The mammary glands of virgin transgenic mice resemble those from wild-type mice in mid-pregnancy but have shown inappropriate expression of $\beta$-casein, cyclin D1 and $\beta$-catenin proteins. Interestingly, progesterone receptor-B isoform (Pgr-B) expression was down regulated, whereas the progesterone receptor-A $(\operatorname{Pgr}-A)$ isoform was upregulated in MTA1-Tg mice. Increased expression of Pgr-A resulted in upregulation of $\mathrm{PgR}$ target genes such as $B c l-X L$ and cyclin D1 leading to delayed involution. The results of the study indicated the possible role of MTA1 in mammary gland during branching morphogenesis and alveologenesis.

MTA1s, the short variant of MTA1, has been shown to suppress ER transcription by sequestering the receptor into the cytoplasm (Kumar et al., 2002). MTA1s role in mammary gland development was analyzed by transgenic approach by the same group that generated the MTA1 transgenic mice (Kumar et al., 2010). MTA1s-Tg mammary glands displayed extensive hyperbranching and increased proliferation of ductal and alveolar epithelial cells, which mimicked the phenotypic changes found 
in the Wnt-Tg mice. Overexpression of MTA1s in HC11, a lactogenic differentiation cell line, activated Wnt1 signaling through MAPK and GSK3-beta pathways, resulting in increased stabilization and nuclear accumulation of $\beta$-catenin. Furthermore, mammary glands from the virgin MTA1s-Tg mice showed ductal hyperplasia and ductal carcinoma in situ. These findings indicate a possible requirement of MTA1s in mammary gland development during ductal branching and alveologenesis similar to MTA1.

MTA3 also forms a cell type-specific Mi2-NuRD complex. MTA3 has been shown to act as a direct transcriptional repressor of Snail, a master regulator of the epithelial-to-mesenchymal transition (EMT) (Fujita et al., 2003). The role of MTA3 in mammary gland development was explored using a transgenic approach (Zhang et al., 2006). Targeted overexpression of Mta3 in the mouse mammary gland resulted in a pronounced defect in ductal side branching both in virgin mice and in the early stages of pregnancy, a contrasting phenotype observed in MTA1Tg mice. Though the mammary glands of both MTA3-Tg mice and wild type mice were similar at early developmental stages, drastic reduction in secondary and tertiary ductal side branching were observed in the Tg mice. This hypobranching phenotype of mammary gland in MTA3 was comparable to the defective branching in Wnt4 KO mice (Brisken et al., 2000). Further, molecular analysis revealed that the reduced ductal branching is due to suppression of Wnt4 expression by MTA3-NuRD complex (Zhang et al., 2006). The comparative summary indicates contrasting roles for MTA1 and MTA3 in mammary gland development.

\section{PROHIBITIN}

Prohibitin (PHB) and REA (Repressor of ER activity), also known as PHB2, belong to a family of proteins that contain an evolutionarily conserved domain, the prohibitin homology domain. PHB plays a diverse role in cellular differentiation, anti-proliferation and morphogenesis (Chowdhury et al., 2014). Overexpression of PHB in breast cancer cells suppresses the ER transcriptional activity, whereas depletion increases the expression of ER target genes (He et al., 2008). PHB interacts with HDAC1 through its coiled domain which partly explains its corepressor activity on ER transactivation functions (He et al., 2008).

The role of PHB in mammary gland development was investigated in $\mathrm{Phb} \mathrm{b}^{+/-}$heterozygous mice since complete deletion of $\mathrm{Phb}$ gene leads to embryonic lethality ( $\mathrm{He}$ et al., 2008). PHB being a corepressor of ER in cultured cells, it is expected to show a hyper proliferative phenotype in the mammary glands of $\mathrm{Phb}^{+/-}$mice. Consistent with this notion, $\mathrm{Phb} \mathrm{b}^{+/-}$mice displayed increased alveolar lateral budding and ductal side-branching in the hormone-treated mammary gland. The increased level of cyclin D1, a direct target of ER, in $P h b^{+/-}$mice compared to wild type mice was attributed to this hyper-proliferative state in $\mathrm{Phb}^{+/-}$mice (He et al., 2008). Accelerated mammary growth in response to steroid hormone treatment was also seen in $\mathrm{Phb} \mathrm{b}^{+/-}$mice suggesting an important in vivo role for the $\mathrm{PHB}$ as a corepressor for ER in controlling steroid-induced mammary morphogenesis.

\section{REA}

Repressor of ER activity (REA) was initially identified as an ER interacting protein using dominant negative ER as bait in two-hybrid screening assays (Montano et al., 1999). REA displays its corepressor functions by enhancing the binding of anti-estrogens such as SERMs to ER. Though REA contains an LXXLL motif near its N-terminus, this motif does not participate in the binding of REA to ER. Rather the C-terminal half of REA interacts with ligand-binding domain of ER. REA functionally competes with coactivators like SRC1 to modulate ER transcriptional activity which partly explains the corepressor activity of REA on ER-mediated transcription (Delage-Mourroux et al., 2000). Further, it was shown that PTalpha (Prothymosin), another coactivator of ER, antagonizes REA inhibitory action toward ER transcriptional activity by replacing the repressive REA protein away from ER (Martini et al., 2000).

Deletion of both the alleles of REA (PHB2) results in embryonic lethality similar to $\mathrm{PHB}$, whereas heterozygous mice $\left(\mathrm{Rea}^{+/-}\right)$display mammary ductal elongation in virgin animals and, increased lobuloalveolar development during pregnancy followed by delayed mammary gland involution after weaning (Mussi et al., 2006). Since, REA displays corepressor activity on ER, these morphological phenotypes of $\mathrm{Rea}^{+/-}$mice reflected the increased cell proliferation and ER transcriptional activities. Recently, tissue-specific conditional $\mathrm{KO}$ approach was used to investigate the consequences of complete loss of Rea in mammary gland (Park et al., 2011). Conditionally deleting one allele or both alleles of the Rea gene at different stages of mammary gland development resulted in different mammary phenotypes (Park et al., 2011). During puberty, mice homozygous null for Rea in the mammary gland showed severely impaired mammary ductal elongation and morphogenesis, whereas mice heterozygous for Rea displayed accelerated mammary ductal elongation and increased numbers of TEBs. In addition, Rea mice showed an up-regulation of amphiregulin, the major paracrine mediator of E2-induced ductal morphogenesis. During pregnancy and lactation, mice with homozygous Rea gene deletion in mammary epithelium showed a loss of lobuloalveolar structures and increased apoptosis of mammary alveolar epithelium, leading to impaired milk production and significant reduction in growth of their offspring. These studies imply that REA is essential for mammary gland development and, has a gene dosage-dependent role in the regulation of stage-specific physiological functions of the mammary glands (Park et al., 2011).

\section{RIP140}

Receptor-interacting protein 140 (RIP140) was initially identified as an ER interacting factor in vitro (Cavailles et al., 1995). Later, it was found to be involved in various regulatory feedback loops and inhibitory cross talks involving several nuclear receptors (White et al., 2004). Though, RIP140 was initially characterized as a nuclear receptor coregulator based on its ability to coactivate steroid hormone receptors, subsequent studies indicated that it can also act as a corepressor (Cavailles et al., 1995; Nautiyal et al., 2013). RIP140 inhibits ER-dependent transcription by competing 
with coactivators and, also by recruiting histone deacetylases (HDACs) to target gene chromatin (Castet et al., 2004).

RIP140 is expressed in both mammary epithelium and stroma, and its role in the development of mammary gland was assessed using knockout and transgeneic approaches. At puberty, Rip140 KO mice lacked TEBs at the tips of the ducts, but at maturity ( 5 months old), in Rip140 KO mice the mammary tree was relatively less branched as compared to heterozygous and wild type mice (Nautiyal et al., 2013). On the other hand, Rip140 overexpressing mice exhibited large primary ducts, hyperplasic growth and TEBs. Further, Rip140-Tg mice developed larger and denser alveolar structures in mammary epithelium indicating that Rip140 can influence alveologenesis. The molecular mechanism of the role of Rip140 in mammary gland development has been attributed to its function as a corepressor that recruited with ER to its target gene promoters including Areg, Pgr, Ccnd1, and Gata3 (Nautiyal et al., 2013). In summary, expression of RIP140 in both mammary epithelial and stromal compartments is required for ductal elongation during puberty and silencing of RIP140 expression leads to a complete loss of the mammary epithelium. These in vivo studies thus imply that RIP140 is certainly a coregulator for ER.

\section{THE ER SIGNALING IN CELL FATE DECISIONS E2 SIGNALING AND ER STATUS IN MAMMARY STEM CELLS (MaSC)}

Cell fate is simply defined as cellular specification or determination with a unique character and behavior. Tissue transplantation experiments combined with lineage tracing approaches using mouse models provided significant advancement in understanding the mammary cell fate (Stingl, 2009; Van Amerongen et al., 2012). The present understanding suggests that a functional epithelium can be regenerated from mammary stem cells upon transplantation into cleared fat pads. Mammary epithelium contains progenitors that give rise to ductal system and contractile myoepithelium because of their pluripotent capacity (Rosen, 2012). Two main lineages of mammary epithelium, namely luminal epithelial cells and basal myoepithelial cells, generate a functional epithelium. The luminal cells are the ducts that form the milk-secreting cells of the alveoli, whereas the myoepithelial cells that form a layer on the luminal epithelium along the ducts helps in milk secretion during lactation. The luminal cells may be either ER positive (ER+) or ER negative $(\mathrm{ER}-$ ) but the luminal progenitors are predominantly ER-, with a small number of them being $\mathrm{ER}^{+}$(Regan et al., 2012). The ER+ cells are hormone responsive and support paracrine signaling in luminal epithelium, whereas the ER-luminal cells include the milk secretory cells (Regan et al., 2012). Therefore, all three populations of cells that include myoepithelial, ER+ and ER - luminal cells constitute the differentiated cells of mammary epithelium. Both myoepithelial and luminal lineages can also be derived from the TEBs or TEBs implying that TEBs carry stem cells and progenitor features (Srinivasan et al., 2003). Mammary stem cells require estrogen signaling as ovariectomy in mice markedly diminishes mammary stem cells (MaSC) number and their outgrowth potential in vivo indicating a role for E2 in self renewal and maintenance of stemness (Asselin-Labat et al., 2010).

\section{PIONEER FACTORS IN MAMMARY CELL FATE}

In general, the cell fate decisions are driven by tissue-specific transcription factors (TFs) based on the cell fate determination signals. A set of transcription factors forming a genetic network with a defined regulatory system controls cell fate determination and subsequently organ development. A well orchestrated network of interactions between such transcription factors and their associated proteins play a regulatory role during organogenesis and development (Davidson and Erwin, 2006; Raouf et al., 2008). Emerging studies have shown that ER functionally interacts with "pioneer factors" in a coordinated fashion to control the mammary gland cell fate (Jozwik and Carroll, 2012). "Pioneer factors" are transcription factors that can directly bind to condensed chromatin and can bring either positive or negative transcriptional outcomes by recruiting other transcription factors and/or histone modification enzymes (Magnani et al., 2011b; Jozwik and Carroll, 2012). In the recent past, FOXA1, GATA3, PBX1 and AP2gamma are characterized as pioneer factors of ER that play crucial role in decisions regarding fate of cells in mammary gland development (Schuur et al., 2001; Kouros-Mehr et al., 2006; Magnani et al., 2011a).

\section{F0XA1}

FOXA1, a member of the forkhead transcription factor family, participates in pioneer function of the genome regulation (Sekiya et al., 2009). FOXA1 is the first pioneer factor identified for the ER and it co-expresses with ER during mammary gland development, primary breast tumors and cell lines (Carroll et al., 2005; Bernardo et al., 2010). Chromatin binding studies revealed that FOXA1 binds at more than $50 \%$ of ER binding sites suggesting that FOXA1 is a key regulator of ER functions in mammary gland development (Hurtado et al., 2011).

FOXA1 is expressed in TEBs, particularly in a subset of luminal cells that are $\mathrm{CD}_{61}{ }^{+}$, while it is not expressed in myoepithelial cells (Bernardo et al., 2010). The pattern of expression of FOXA1 matches with ER in the pubertal gland. Because of its critical role in regulation of ER transcription functions and similarity in the expression pattern with ER, KO mouse studies revealed that deficiency of Foxal in mouse leads to defects in hormone-induced mammary ductal invasion associated with a loss of TEB formation (Bernardo et al., 2010). It implies that FOXA1 is essential for the ductal outgrowth during puberty. However, Foxal expression is not required for embryonic development of the mammary ductal rudiment similar to ER. Nevertheless, analysis of mammary glands in Foxal null mice revealed that it is not important for alveologenesis as Foxa1 null glands could form milk-producing alveoli which are unlikely in Esr1 null mice. This suggests that Foxal functions are probably restricted to ductal epithelium and independent of alveologenesis. Because of the similarities between the expression pattern and functions in mammary gland, transcriptional interaction between FOXA1 and ER was verified. This analysis indicated that FOXA1 regulates ER expression in luminal cells by directly associating at 10 distinct regions of the Esr 1 gene, with five sites in the promoter region and five in intragenic regions (Bernardo et al., 2010). It implies that FOXA1 contributes to ER functionality and mammary cell fate by modulating the basal expression and functional activity of ER. 


\section{GATA3}

GATA3 is a member of GATA transcription factors that participate in development of various organs in the body (Ho and Pai, 2007). Recent reports suggest a pivotal role for GATA3 in mammary gland morphogenesis, particularly in luminal cell differentiation (Kouros-Mehr et al., 2006; Asselin-Labat et al., 2007). GATA3 was identified as highly enriched transcription factor in a microarray screening of mammary epithelium (Kouros-Mehr et al., 2006). During embryonic development, GATA3 expression is detected at E12.5 day in primordial mammary buds (AsselinLabat et al., 2007) and is confined only to mammary epithelial layer, but not in myoepithelium. Its restricted expression to luminal cell lineages indicates a potential role in the regulation of epithelial cell phenotype of mammary gland development. In consistent with its expression, deletion of Gata3 results in severe defects in mammary development due to failure in TEB formation during puberty. This phenotype is similar to that observed in loss of ER and it can be further attributed to the failure of the expansion of the luminal progenitor population (KourosMehr et al., 2006). During pregnancy, GATA3 seems to participate in luminal epithelial differentiation required for lobuloalveolar development. The targeted deletion of Gata3 from progenitor cells blocks luminal cell differentiation, whereas forced expression of GATA3 in mammary stem-cell-enriched populations promotes differentiation into luminal cells. These studies strengthen the fact that GATA3 is required not only to maintain the luminal epithelial lineage, but also in the determination of their cell fate (Asselin-Labat et al., 2007).

An intriguing question is that how are GATA3 functions related to ER? Similar to Esr1 KO mice, conditional deletion of Gata3 led to the impairment in the TEBs formation suggesting a functional overlap between these two factors. Although GATA3 and ER pathways may have few non-overlapping functions in mammary luminal cells, FOXA1 bridges the link between ER and GATA3 (Kouros-Mehr et al., 2008). The GATA3 functions are truly integrated into E2 signaling pathway as both of them regulate each other's expression in luminal cells (Kouros-Mehr et al., 2006). GATA3 regulates FOXA1, which in turn mediates ER expression. Further, ER induces GATA3 expression in luminal cells implying that there is an interdependence of FOXA1, ER and GATA3 in the maintenance of luminal cells (Figure 3). Not only that these three transcription factors depend on the transcription of the other, they also colocalize at genomic sites after ligand stimulation results in the formation of a tripartite enhanceosome complex of ER $\alpha$, FOXA1, and GATA3. This complex further ensures the optimal transcriptional activation by recruiting RNA ploII and p300 to the target gene chromatin (Kong et al., 2011). FOXM1, a forkhead transcription factor, is shown to down regulate GATA3 expression through methylation of the GATA3 promoter in association with DNMT3b, a DNA methyl transferase. Therefore, FOXM1 promotes luminal proliferation by opposing GATA3-mediated luminal differentiation in the mammary gland (Carr et al., 2012). Foxm1 is an E2 inducible gene (Millour et al., 2010). Therefore, Foxm1 induction by E2-ER may balance the functional interaction between ER and GATA3 during mammary gland. Taken together, an intricate network of transcription factors involving GATA3,

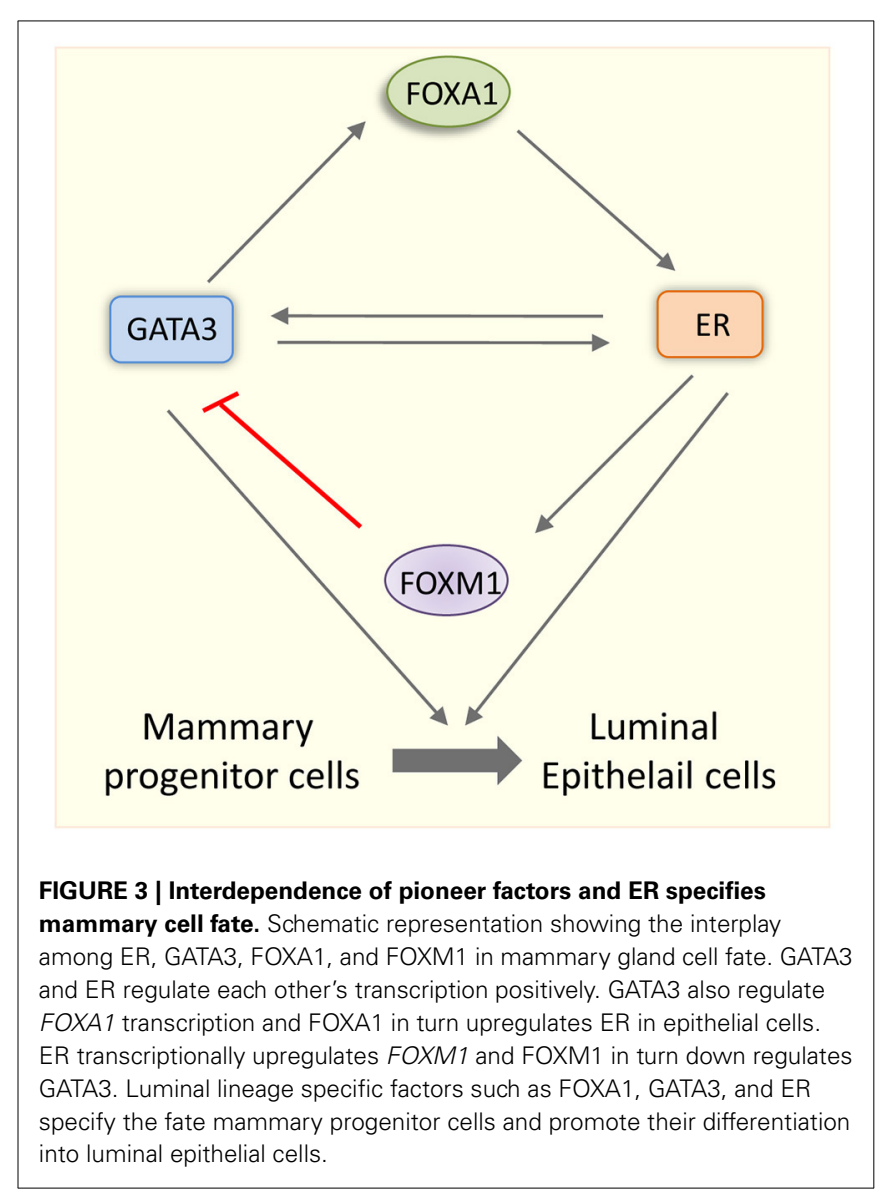

FOXA1, FOXM1, and ER dictates the fate of the mammary cell (Figure 3).

\section{CONCLUDING REMARIS}

Considering the significant role played by coregulators in ER action, investigation on identification and characterization of new coregulators for ER continues to be an interesting area of research. On the other hand, knowledge on the intricate mechanisms that underlie the coregulator-mediated actions on ER signaling is rapidly expanding. Although, the in vitro roles of coregulators on ER functionality and cellular functions are determined, information available on the in vivo roles for ER coregulators is limited, considering the large number of known coregulators for ER. This could be due to the fact that complete ablation of the genes of several coregulators led to embryonic lethality. Therefore, in future there is a demand for the utilization of mammary gland-specific conditional $\mathrm{KO}$ approach in murine models to address this issue. In vivo studies using murine $\mathrm{KO}$ models indicated that coregulators like SRC-3, CITED-1 and cyclin D1, and pioneer factors such as FOXA1 and GATA3 are important for the development of pubertal mammary gland. Some coregulators appear to be important in the later stages of mammary gland development, it can be implied that coregulators do not follow a thumb rule in mammary gland development. Balanced expression through interdependency mechanisms among ER, FOXA1, and GATA3 specifies fate of the luminal cell. Considering their established role 
in mammary gland development and breast cancer, mutant mice models of these coregulators can be further explored for clinical studies in the future. Obtaining the blueprint of all the coregulators and their role in mammary gland development may further offer therapeutic strategies to develop coregulator-based therapies to treat breast cancers.

\section{ACKNOWLEDGMENTS}

This work is supported by DBT grants No- BT-BRB-TF-42013; BT/01/IYBA/2009 and BT/PR11114/BRB/10/635/2008; and DST grant No- SB/S0/BB/013/2013, India (to Bramanandam Manavathi). Authors thank Dr. Suresh Yenugu, Dr. G Madhu Babu and Ms Oindrilla Dey, School of Life Sciences, University of Hyderabad for critical reading of the manuscript.

\section{REFERENCES}

Asselin-Labat, M. L., Sutherland, K. D., Barker, H., Thomas, R., Shackleton, M., Forrest, N. C., et al. (2007). Gata-3 is an essential regulator of mammary-gland morphogenesis and luminal-cell differentiation. Nat. Cell Biol. 9, 201-209. doi: $10.1038 /$ ncb 1530

Asselin-Labat, M. L., Vaillant, F., Sheridan, J. M., Pal, B., Wu, D., Simpson, E. R., et al. (2010). Control of mammary stem cell function by steroid hormone signalling. Nature 465, 798-802. doi: 10.1038/nature09027

Bagheri-Yarmand, R., Talukder, A. H., Wang, R. A., Vadlamudi, R. K., and Kumar, R. (2004). Metastasis-associated protein 1 deregulation causes inappropriate mammary gland development and tumorigenesis. Development 131, 3469-3479. doi: 10.1242/dev.01213

Bernardo, G. M., Lozada, K. L., Miedler, J. D., Harburg, G., Hewitt, S. C., Mosley, J. D., et al. (2010). FOXA1 is an essential determinant of ERalpha expression and mammary ductal morphogenesis. Development 137, 2045-2054. doi: 10.1242/dev.043299

Brisken, C., Heineman, A., Chavarria, T., Elenbaas, B., Tan, J., Dey, S. K., et al. (2000). Essential function of Wnt-4 in mammary gland development downstream of progesterone signaling. Genes Dev. 14, 650-654. doi: 10.1101/gad.14.6.650

Brisken, C., and O'malley, B. (2010). Hormone action in the mammary gland. Cold Spring Harb. Perspect. Biol. 2, a003178. doi: 10.1101/cshperspect.a003178

Buckley, N. E., Conlon, S. J., Jirstrom, K., Kay, E. W., Crawford, N. T., O’grady, A., et al. (2011). The DeltaNp63 proteins are key allies of BRCA1 in the prevention of basal-like breast cancer. Cancer Res. 71, 1933-1944. doi: 10.1158/00085472.CAN-10-2717

Caizzi, L., Ferrero, G., Cutrupi, S., Cordero, F., Ballare, C., Miano, V., et al. (2014). Genome-wide activity of unliganded estrogen receptor-alpha in breast cancer cells. Proc. Natl. Acad. Sci. U.S.A. 111, 4892-4897. doi: 10.1073/pnas.1315445111

Carr, J. R., Kiefer, M. M., Park, H. J., Li, J., Wang, Z., Fontanarosa, J., et al. (2012). FoxM1 regulates mammary luminal cell fate. Cell Rep. 1, 715-729. doi: 10.1016/j.celrep.2012.05.005

Carroll, J. S., Liu, X. S., Brodsky, A. S., Li, W., Meyer, C. A., Szary, A. J., et al. (2005). Chromosome-wide mapping of estrogen receptor binding reveals longrange regulation requiring the forkhead protein FoxA1. Cell 122, 33-43. doi: 10.1016/j.cell.2005.05.008

Casimiro, M. C., Wang, C., Li, Z., Di Sante, G., Willmart, N. E., Addya, S., et al. (2013). Cyclin D1 determines estrogen signaling in the mammary gland in vivo. Mol. Endocrinol. 27, 1415-1428. doi: 10.1210/me.2013-1065

Castet, A., Boulahtouf, A., Versini, G., Bonnet, S., Augereau, P., Vignon, F., et al. (2004). Multiple domains of the receptor-interactingprotein 140 contribute to transcription inhibition. Nucleic Acids Res. 32, 1957-1966. doi: 10.1093/nar/gkh524

Catoe, H. W., and Nawaz, Z. (2011). E6-AP facilitates efficient transcription at estrogen responsive promoters through recruitment of chromatin modifiers. Steroids 76, 897-902. doi: 10.1016/j.steroids.2011.04.007

Cavailles, V., Dauvois, S., L'horset, F., Lopez, G., Hoare, S., Kushner, P. J., et al. (1995). Nuclear factor RIP140 modulates transcriptional activation by the estrogen receptor. EMBO J. 14, 3741-3751.
Chen, D., Huang, S. M., and Stallcup, M. R. (2000). Synergistic, p160 coactivatordependent enhancement of estrogen receptor function by CARM1 and p300. J. Biol. Chem. 275, 40810-40816. doi: 10.1074/jbc.M005459200

Chen, D., Ma, H., Hong, H., Koh, S. S., Huang, S. M., Schurter, B. T., et al. (1999). Regulation of transcription by a protein methyltransferase. Science 284, 2174-2177.

Chowdhury, I., Thompson, W. E., and Thomas, K. (2014). Prohibitins role in cellular survival through Ras-Raf-MEK-ERK pathway. J. Cell. Physiol. 229, 998-1004. doi: $10.1002 /$ jcp. 24531

Dasgupta, S., Lonard, D. M., and O'malley, B. W. (2014). Nuclear receptor coactivators: master regulators of human health and disease. Annu. Rev. Med. 65, 279-292. doi: 10.1146/annurev-med-051812-145316

Davidson, E. H., and Erwin, D. H. (2006). Gene regulatory networks and the evolution of animal body plans. Science 311, 796-800. doi: 10.1126/science.11 13832

Delage-Mourroux, R., Martini, P. G., Choi, I., Kraichely, D. M., Hoeksema, J., and Katzenellenbogen, B. S. (2000). Analysis of estrogen receptor interaction with a repressor of estrogen receptor activity (REA) and the regulation of estrogen receptor transcriptional activity by REA. J. Biol. Chem. 275, 35848-35856. doi: 10.1074/jbc.M001327200

Eakin, C. M., Maccoss, M. J., Finney, G. L., and Klevit, R. E. (2007). Estrogen receptor alpha is a putative substrate for the BRCA1 ubiquitin ligase. Proc. Natl. Acad. Sci. U.S.A. 104, 5794-5799. doi: 10.1073/pnas.0610887104

Echeverria, P. C., and Picard, D. (2010). Molecular chaperones, essential partners of steroid hormone receptors for activity and mobility. Biochim. Biophys. Acta 1803, 641-649. doi: 10.1016/j.bbamcr.2009.11.012

Ewan, K. B., Shyamala, G., Ravani, S. A., Tang, Y., Akhurst, R., Wakefield, L., et al. (2002). Latent transforming growth factor-beta activation in mammary gland: regulation by ovarian hormones affects ductal and alveolar proliferation. Am. J. Pathol. 160, 2081-2093. doi: 10.1016/S0002-9440(10)61158-3

Fan, S., Ma, Y. X., Wang, C., Yuan, R. Q., Meng, Q., Wang, J. A., et al. (2001). Role of direct interaction in BRCA1 inhibition of estrogen receptor activity. Oncogene 20, 77-87. doi: 10.1038/sj.onc.1204073

Fan, S., Ma, Y. X., Wang, C., Yuan, R. Q., Meng, Q., Wang, J. A., et al. (2002). p300 Modulates the BRCA1 inhibition of estrogen receptor activity. Cancer Res. 62, 141-151.

Fan, S., Wang, J., Yuan, R., Ma, Y., Meng, Q., Erdos, M. R., et al. (1999). BRCA1 inhibition of estrogen receptor signaling in transfected cells. Science 284, 1354-1356.

Fantl, V., Edwards, P. A., Steel, J. H., Vonderhaar, B. K., and Dickson, C. (1999). Impaired mammary gland development in Cyl-1(-/-) mice during pregnancy and lactation is epithelial cell autonomous. Dev. Biol. 212, 1-11. doi: 10.1006/dbio.1999.9329

Feng, Y., Manka, D., Wagner, K. U., and Khan, S. A. (2007). Estrogen receptoralpha expression in the mammary epithelium is required for ductal and alveolar morphogenesis in mice. Proc. Natl. Acad. Sci. U.S.A. 104, 14718-14723. doi: 10.1073/pnas.0706933104

Fujita, N., Jaye, D. L., Kajita, M., Geigerman, C., Moreno, C. S., and Wade, P. A. (2003). MTA3, a Mi-2/NuRD complex subunit, regulates an invasive growth pathway in breast cancer. Cell 113, 207-219. doi: 10.1016/S00928674(03)00234-4

Fullwood, M. J., Liu, M. H., Pan, Y. F., Liu, J., Xu, H., Mohamed, Y. B., et al. (2009). An oestrogen-receptor-alpha-bound human chromatin interactome. Nature 462, 58-64. doi: 10.1038/nature08497

Gao, X., Mohsin, S. K., Gatalica, Z., Fu, G., Sharma, P., and Nawaz, Z. (2005). Decreased expression of e6-associated protein in breast and prostate carcinomas. Endocrinology 146, 1707-1712. doi: 10.1210/en.2004-1198

Gehin, M., Mark, M., Dennefeld, C., Dierich, A., Gronemeyer, H., and Chambon, P. (2002). The function of TIF2/GRIP1 in mouse reproduction is distinct from those of SRC-1 and p/CIP. Mol. Cell. Biol. 22, 5923-5937. doi 10.1128/MCB.22.16.5923-5937.2002

Gertz, J., Reddy, T. E., Varley, K. E., Garabedian, M. J., and Myers, R. M. (2012). Genistein and bisphenol A exposure cause estrogen receptor 1 to bind thousands of sites in a cell type-specific manner. Genome Res. 22, 2153-2162. doi: 10.1101/gr.135681.111

Gorski, J. J., Kennedy, R. D., Hosey, A. M., and Harkin, D. P. (2009). The complex relationship between BRCA1 and ERalpha in hereditary breast cancer. Clin. Cancer Res. 15, 1514-1518. doi: 10.1158/1078-0432.CCR08-0640 
Han, S. J., Lonard, D. M., and O'malley, B. W. (2009). Multi-modulation of nuclear receptor coactivators through posttranslational modifications. Trends Endocrinol. Metab. 20, 8-15. doi: 10.1016/j.tem.2008.10.001

Hasegawa, N., Sumitomo, A., Fujita, A., Aritome, N., Mizuta, S., Matsui, K., et al. (2012). Mediator subunits MED1 and MED24 cooperatively contribute to pubertal mammary gland development and growth of breast carcinoma cells. Mol. Cell. Biol. 32, 1483-1495. doi: 10.1128/MCB.05245-11

He, B., Feng, Q., Mukherjee, A., Lonard, D. M., Demayo, F. J., Katzenellenbogen, B. S., et al. (2008). A repressive role for prohibitin in estrogen signaling. Mol. Endocrinol. 22, 344-360. doi: 10.1210/me.2007-0400

Heery, D. M., Kalkhoven, E., Hoare, S., and Parker, M. G. (1997). A signature motif in transcriptional co-activators mediates binding to nuclear receptors. Nature 387, 733-736. doi: $10.1038 / 42750$

Ho, I. C., and Pai, S. Y. (2007). GATA-3 - not just for Th2 cells anymore. Cell Mol. Immunol. 4, 15-29.

Hosey, A. M., Gorski, J. J., Murray, M. M., Quinn, J. E., Chung, W. Y., Stewart, G. E., et al. (2007). Molecular basis for estrogen receptor alpha deficiency in BRCA1-linked breast cancer. J. Natl. Cancer Inst. 99, 1683-1694. doi: 10.1093/jnci/djm207

Howlin, J., Mcbryan, J., Napoletano, S., Lambe, T., Mcardle, E., Shioda, T., et al. (2006). CITED1 homozygous null mice display aberrant pubertal mammary ductal morphogenesis. Oncogene 25, 1532-1542. doi: 10.1038/sj.onc. 1209183

Hu, X., and Lazar, M. A. (1999). The CoRNR motif controls the recruitment of corepressors by nuclear hormone receptors. Nature 402, 93-96. doi: $10.1038 / 47069$

Hurtado, A., Holmes, K. A., Ross-Innes, C. S., Schmidt, D., and Carroll, J. S. (2011). FOXAl is a key determinant of estrogen receptor function and endocrine response. Nat. Genet. 43, 27-33. doi: 10.1038/ng.730

Jiang, P., Hu, Q., Ito, M., Meyer, S., Waltz, S., Khan, S., et al. (2010). Key roles for MED1 LxxLL motifs in pubertal mammary gland development and luminal-cell differentiation. Proc. Natl. Acad. Sci. U.S.A. 107, 6765-6770. doi: 10.1073/pnas.1001814107

Jozwik, K. M., and Carroll, J. S. (2012). Pioneer factors in hormone-dependent cancers. Nat. Rev. Cancer 12, 381-385. doi: 10.1038/nrc3263

Kawai, H., Li, H., Chun, P., Avraham, S., and Avraham, H. K. (2002). Direct interaction between BRCA1 and the estrogen receptor regulates vascular endothelial growth factor (VEGF) transcription and secretion in breast cancer cells. Oncogene 21, 7730-7739. doi: 10.1038/sj.onc.1205971

Klein-Hitpass, L., Ryffel, G. U., Heitlinger, E., and Cato, A. C. (1988). A 13 bp palindrome is a functional estrogen responsive element and interacts specifically with estrogen receptor. Nucleic Acids Res. 16, 647-663.

Klinge, C. M. (2000). Estrogen receptor interaction with co-activators and corepressors. Steroids 65, 227-251. doi: 10.1016/S0039-128X(99)00107-5

Kong, S. L., Li, G., Loh, S. L., Sung, W. K., and Liu, E. T. (2011). Cellular reprogramming by the conjoint action of ER $\alpha$, FOXA1, and GATA3 to a ligand-inducible growth state. Mol. Syst. Biol. 30, 526. doi: 10.1038/msb.2011.59

Kouros-Mehr, H., Kim, J. W., Bechis, S. K., and Werb, Z. (2008). GATA-3 and the regulation of the mammary luminal cell fate. Curr. Opin. Cell Biol. 20, 164-170. doi: $10.1016 /$ j.ceb.2008.02.003

Kouros-Mehr, H., Slorach, E. M., Sternlicht, M. D., and Werb, Z. (2006). GATA-3 maintains the differentiation of the luminal cell fate in the mammary gland. Cell 127, 1041-1055. doi: 10.1016/j.cell.2006.09.048

Kumar, R., Balasenthil, S., Pakala, S. B., Rayala, S. K., Sahin, A. A., and Ohshiro, K. (2010). Metastasis-associated protein 1 short form stimulates Wntl pathway in mammary epithelial and cancer cells. Cancer Res. 70, 6598-6608. doi: 10.1158/0008-5472.CAN-10-0907

Kumar, R., Wang, R. A., Mazumdar, A., Talukder, A. H., Mandal, M., Yang, Z., et al. (2002). A naturally occurring MTA1 variant sequesters oestrogen receptoralpha in the cytoplasm. Nature 418, 654-657. doi: 10.1038/nature00889

Lamb, J., Ladha, M. H., Mcmahon, C., Sutherland, R. L., and Ewen, M. E. (2000). Regulation of the functional interaction between cyclin D1 and the estrogen receptor. Mol. Cell. Biol. 20, 8667-8675. doi: 10.1128/MCB.20.23.86678675.2000

Lieberman-Aiden, E., Van Berkum, N. L., Williams, L., Imakaev, M., Ragoczy, T., Telling, A., et al. (2009). Comprehensive mapping of long-range interactions reveals folding principles of the human genome. Science 326, 289-293. doi: $10.1126 /$ science. 1181369

Lonard, D. M., Lanz, R. B., and O'malley, B. W. (2007). Nuclear receptor coregulators and human disease. Endocr. Rev. 28, 575-587. doi: 10.1210/er.2007-0012
Lonard, D. M., and O'malley, B. W. (2006). The expanding cosmos of nuclear receptor coactivators. Cell 125, 411-414. doi: 10.1016/j.cell.2006.04.021

Lonard, D. M., and O'malley, B. W. (2007). Nuclear receptor coregulators: judges, juries, and executioners of cellular regulation. Mol. Cell 27, 691-700. doi: 10.1016/j.molcel.2007.08.012

Magnani, L., Ballantyne, E. B., Zhang, X., and Lupien, M. (2011a). PBX1 genomic pioneer function drives ERalpha signaling underlying progression in breast cancer. PLoS Genet. 7:e1002368. doi: 10.1371/journal.pgen.1002368

Magnani, L., Eeckhoute, J., and Lupien, M. (2011b). Pioneer factors: directing transcriptional regulators within the chromatin environment. Trends Genet. 27, 465-474. doi: 10.1016/j.tig.2011.07.002

Malik, S., Guermah, M., Yuan, C. X., Wu, W., Yamamura, S., and Roeder, R. G. (2004). Structural and functional organization of TRAP220, the TRAP/mediator subunit that is targeted by nuclear receptors. Mol. Cell. Biol. 24, 8244-8254. doi: 10.1128/MCB.24.18.8244-8254.2004

Mallepell, S., Krust, A., Chambon, P., and Brisken, C. (2006). Paracrine signaling through the epithelial estrogen receptor alpha is required for proliferation and morphogenesis in the mammary gland. Proc. Natl. Acad. Sci. U.S.A. 103, 2196-2201. doi: 10.1073/pnas.0510974103

Manavathi, B., and Kumar, R. (2007). Metastasis tumor antigens, an emerging family of multifaceted master coregulators. J. Biol. Chem. 282, 1529-1533. doi: 10.1074/jbc.R600029200

Manavathi, B., Dey, O., Gajulapalli, V. N., Bhatia, R. S., Bugide, S., and Kumar, R. (2013). Derailed estrogen signaling and breast cancer: an authentic couple. Endocr. Rev. 34, 1-32. doi: 10.1210/er.2011-1057

Manavathi, B., Peng, S., Rayala, S. K., Talukder, A. H., Wang, M. H., Wang, R. A., et al. (2007). Repression of Six 3 by a corepressor regulates rhodopsin expression. Proc. Natl. Acad. Sci. U.S.A. 104, 13128-13133. doi: 10.1073/pnas.07058 78104

Martini, P. G., Delage-Mourroux, R., Kraichely, D. M., and Katzenellenbogen, B. S. (2000). Prothymosin alpha selectively enhances estrogen receptor transcriptional activity by interacting with a repressor of estrogen receptor activity. Mol. Cell. Biol. 20, 6224-6232. doi: 10.1128/MCB.20.17.6224-6232.2000

Mazumdar, A., Wang, R. A., Mishra, S. K., Adam, L., Bagheri-Yarmand, R., Mandal, M., et al. (2001). Transcriptional repression of oestrogen receptor by metastasisassociated protein 1 corepressor. Nat. Cell Biol. 3, 30-37. doi: 10.1038/35050532

Mcinerney, E. M., Rose, D. W., Flynn, S. E., Westin, S., Mullen, T. M., Krones, A., et al. (1998). Determinants of coactivator LXXLL motif specificity in nuclear receptor transcriptional activation. Genes Dev. 12, 3357-3368.

Miki, Y., Swensen, J., Shattuck-Eidens, D., Futreal, P. A., Harshman, K., Tavtigian, S., et al. (1994). A strong candidate for the breast and ovarian cancer susceptibility gene BRCA1. Science 266, 66-71.

Millour, J., Constantinidou, D., Stavropoulou, A. V., Wilson, M. S., Myatt, S. S., Kwok, J. M., et al. (2010). FOXM1 is a transcriptional target of ERalpha and has a critical role in breast cancer endocrine sensitivity and resistance. Oncogene 29, 2983-2995. doi: 10.1038/onc.2010.47

Mishra, S. K., Balasenthil, S., Nguyen, D., and Vadlamudi, R. K. (2004). Cloning and functional characterization of PELP1/MNAR promoter. Gene 330, 115-122. doi: 10.1016/j.gene.2004.01.011

Misiti, S., Schomburg, L., Yen, P. M., and Chin, W. W. (1998). Expression and hormonal regulation of coactivator and corepressor genes. Endocrinology 139, 2493-2500. doi: 10.1210/endo.139.5.5971

Montano, M. M., Ekena, K., Delage-Mourroux, R., Chang, W., Martini, P., and Katzenellenbogen, B. S. (1999). An estrogen receptor-selective coregulator that potentiates the effectiveness of antiestrogens and represses the activity of estrogens. Proc. Natl. Acad. Sci. U.S.A. 96, 6947-6952.

Mueller, S. O., Clark, J. A., Myers, P. H., and Korach, K. S. (2002). Mammary gland development in adult mice requires epithelial and stromal estrogen receptor alpha. Endocrinology 143, 2357-2365. doi: 10.1210/endo.143.6.8836

Mukherjee, A., Soyal, S. M., Fernandez-Valdivia, R., Gehin, M., Chambon, P., Demayo, F. J., et al. (2006). Steroid receptor coactivator 2 is critical for progesterone-dependent uterine function and mammary morphogenesis in the mouse. Mol. Cell. Biol. 26, 6571-6583. doi: 10.1128/MCB.00654-06

Mussi, P., Liao, L., Park, S. E., Ciana, P., Maggi, A., Katzenellenbogen, B. S., et al. (2006). Haploinsufficiency of the corepressor of estrogen receptor activity (REA) enhances estrogen receptor function in the mammary gland. Proc. Natl. Acad. Sci. U.S.A. 103, 16716-16721. doi: 10.1073/pnas.0607768103

Naresh, A., Long, W., Vidal, G. A., Wimley, W. C., Marrero, L., Sartor, C. I., et al. (2006). The ERBB4/HER4 intracellular domain 4ICD is a BH3-only protein 
promoting apoptosis of breast cancer cells. Cancer Res. 66, 6412-6420. doi: 10.1158/0008-5472.CAN-05-2368

Nautiyal, J., Christian, M., and Parker, M. G. (2013). Distinct functions for RIP140 in development, inflammation, and metabolism. Trends Endocrinol. Metab. 24, 451-459. doi: 10.1016/j.tem.2013.05.001

Nawaz, Z., Lonard, D. M., Smith, C. L., Lev-Lehman, E., Tsai, S. Y., Tsai, M. J., et al. (1999). The Angelman syndrome-associated protein, E6-AP, is a coactivator for the nuclear hormone receptor superfamily. Mol. Cell. Biol. 19, 1182-1189.

Nilsson, S., Makela, S., Treuter, E., Tujague, M., Thomsen, J., Andersson, G., et al. (2001). Mechanisms of estrogen action. Physiol. Rev. 81, 1535-1565.

Nishihara, E., Yoshida-Komiya, H., Chan, C. S., Liao, L., Davis, R. L., O'malley, B. W., et al. (2003). SRC-1 null mice exhibit moderate motor dysfunction and delayed development of cerebellar Purkinje cells. J. Neurosci. 23, 213-222.

O'malley, B. W., and Mckenna, N. J. (2008). Coactivators and corepressors: what's in a name? Mol. Endocrinol. 22, 2213-2214. doi: 10.1210/me.2008-0201

O'malley, B. W., Qin, J., and Lanz, R. B. (2008). Cracking the coregulator codes. Curr. Opin. Cell Biol. 20, 310-315. doi: 10.1016/j.ceb.2008.04.005

Onate, S. A., Tsai, S. Y., Tsai, M. J., and O'malley, B. W. (1995). Sequence and characterization of a coactivator for the steroid hormone receptor superfamily. Science 270, 1354-1357.

Ormandy, C. J., Musgrove, E. A., Hui, R., Daly, R. J., and Sutherland, R. L. (2003). Cyclin D1, EMS1 and 11q13 amplification in breast cancer. Breast Cancer Res. Treat. 78, 323-335. doi: 10.1023/A:1023033708204

Park, S., Zhao, Y., Yoon, S., Xu, J., Liao, L., Lydon, J., et al. (2011). Repressor of estrogen receptor activity (REA) is essential for mammary gland morphogenesis and functional activities: studies in conditional knockout mice. Endocrinology 152, 4336-4349. doi: 10.1210/en.2011-1100

Rajan, J. V., Marquis, S. T., Gardner, H. P., and Chodosh, L. A. (1997). Developmental expression of Brca2 colocalizes with Brcal and is associated with proliferation and differentiation in multiple tissues. Dev. Biol. 184, 385-401. doi: 10.1006/dbio. 1997.8526

Ramamoorthy, S., and Nawaz, Z. (2008). E6-associated protein (E6-AP) is a dual function coactivator of steroid hormone receptors. Nucl. Recept. Signal. 6, e006. doi: 10.1621/nrs.06006

Ramamoorthy, S., Tufail, R., Hokayem, J. E., Jorda, M., Zhao, W., Reis, Z., et al. (2012). Overexpression of ligase defective E6-associated protein, E6-AP, results in mammary tumorigenesis. Breast Cancer Res. Treat. 132, 97-108. doi: 10.1007/s10549-011-1567-2

Raouf, A., Zhao, Y., To, K., Stingl, J., Delaney, A., Barbara, M., et al. (2008). Transcriptome analysis of the normal human mammary cell commitment and differentiation process. Cell Stem Cell 3, 109-118. doi: 10.1016/j.stem.2008.05.018

Regan, J. L., Kendrick, H., Magnay, F. A., Vafaizadeh, V., Groner, B., and Smalley, M. J. (2012). c-Kit is required for growth and survival of the cells of origin of Brcal-mutation-associated breast cancer. Oncogene 31, 869-883. doi: 10.1038/onc.2011.289

Rokicki, J., Das, P. M., Giltnane, J. M., Wansbury, O., Rimm, D. L., Howard, B. A., et al. (2010). The ERalpha coactivator, HER4/4ICD, regulates progesterone receptor expression in normal and malignant breast epithelium. Mol. Cancer 9, 150. doi: 10.1186/1476-4598-9-150

Rosen, J. M. (2012). On murine mammary epithelial stem cells: discovery, function, and current status. Cold Spring Harb. Perspect. Biol. 4, a013268. doi: 10.1101/cshperspect.a013268

Ross-Innes, C. S., Stark, R., Teschendorff, A. E., Holmes, K. A., Ali, H. R., Dunning, M. J., et al. (2012). Differential oestrogen receptor binding is associated with clinical outcome in breast cancer. Nature 481, 389-393. doi: 10.1038 /nature 10730

Russo, J., and Russo, I. H. (2004). Development of the human breast. Maturitas 49, 2-15. doi: 10.1016/j.maturitas.2004.04.011

Safe, S. (2001). Transcriptional activation of genes by 17 beta-estradiol through estrogen receptor-Sp1 interactions. Vitam. Horm. 62, 231-252. doi: 10.1016/S0083-6729(01)62006-5

Sanyal, A., Lajoie, B. R., Jain, G., and Dekker, J. (2012). The long-range interaction landscape of gene promoters. Nature 489, 109-113. doi: 10.1038/nature11279

Schuur, E. R., Mcpherson, L. A., Yang, G. P., and Weigel, R. J. (2001). Genomic structure of the promoters of the human estrogen receptor-alpha gene demonstrate changes in chromatin structure induced by AP2gamma. J. Biol. Chem. 276, 15519-15526. doi: 10.1074/jbc.M009001200

Sekiya, T., Muthurajan, U. M., Luger, K., Tulin, A. V., and Zaret, K. S. (2009). Nucleosome-binding affinity as a primary determinant of the nuclear mobility of the pioneer transcription factor FoxA. Genes Dev. 23, 804-809. doi: 10.1101/gad.1775509

Smith, C. L., Devera, D. G., Lamb, D. J., Nawaz, Z., Jiang, Y. H., Beaudet, A. L., et al. (2002). Genetic ablation of the steroid receptor coactivator-ubiquitin ligase, E6-AP, results in tissue-selective steroid hormone resistance and defects in reproduction. Mol. Cell. Biol. 22, 525-535. doi: 10.1128/MCB.22.2.525535.2002

Smith, C. L., and O'malley, B. W. (2004). Coregulator function: a key to understanding tissue specificity of selective receptor modulators. Endocr. Rev. 25, 45-71. doi: 10.1210/er.2003-0023

Spillman, M. A., and Bowcock, A. M. (1996). BRCA1 and BRCA2 mRNA levels are coordinately elevated in human breast cancer cells in response to estrogen. Oncogene 13, 1639-1645.

Srinivasan, K., Strickland, P., Valdes, A., Shin, G. C., and Hinck, L. (2003). Netrin-1/neogenin interaction stabilizes multipotent progenitor cap cells during mammary gland morphogenesis. Dev. Cell 4, 371-382. doi: 10.1016/S15345807(03)00054-6

Stingl, J. (2009). Detection and analysis of mammary gland stem cells. J. Pathol. 217, 229-241. doi: 10.1002/path.2457

Sun, J., Zhou, W., Kaliappan, K., Nawaz, Z., and Slingerland, J. M. (2012). ERalpha phosphorylation at Y537 by Src triggers E6-AP-ERalpha binding, ERalpha ubiquitylation, promoter occupancy, and target gene expression. Mol. Endocrinol. 26, 1567-1577. doi: 10.1210/me.2012-1140

Tanos, T., Rojo, L. J., Echeverria, P., and Brisken, C. (2012). ER and PR signaling nodes during mammary gland development. Breast Cancer Res. 14, 210. doi: $10.1186 / \mathrm{bcr} 3166$

Tidcombe, H., Jackson-Fisher, A., Mathers, K., Stern, D. F., Gassmann, M., and Golding, J. P. (2003). Neural and mammary gland defects in ErbB4 knockout mice genetically rescued from embryonic lethality. Proc. Natl. Acad. Sci. U.S.A. 100, 8281-8286. doi: 10.1073/pnas.143 6402100

Tkocz, D., Crawford, N. T., Buckley, N. E., Berry, F. B., Kennedy, R. D., Gorski, J. J., et al. (2012). BRCA1 and GATA3 corepress FOXC1 to inhibit the pathogenesis of basal-like breast cancers. Oncogene 31, 3667-3678. doi: 10.1038/onc. 2011.531

Van Amerongen, R., Bowman, A. N., and Nusse, R. (2012). Developmental stage and time dictate the fate of Wnt/beta-catenin-responsive stem cells in the mammary gland. Cell Stem Cell 11, 387-400. doi: 10.1016/j.stem.2012. 05.023

Wang, C., Fan, S., Li, Z., Fu, M., Rao, M., Ma, Y., et al. (2005). Cyclin D1 antagonizes BRCA1 repression of estrogen receptor alpha activity. Cancer Res. 65, 6557-6567. doi: 10.1158/0008-5472.CAN-05-0486

Wang, T. C., Cardiff, R. D., Zukerberg, L., Lees, E., Arnold, A., and Schmidt, E. V. (1994). Mammary hyperplasia and carcinoma in MMTV-cyclin D1 transgenic mice. Nature 369, 669-671. doi: 10.1038/369669a0

Welboren, W. J., Van Driel, M. A., Janssen-Megens, E. M., Van Heeringen, S. J., Sweep, F. C., Span, P. N., et al. (2009). ChIP-Seq of ERalpha and RNA polymerase II defines genes differentially responding to ligands. EMBO J. 28, 1418-1428. doi: 10.1038/emboj.2009.88

White, J. H., Fernandes, I., Mader, S., and Yang, X. J. (2004). Corepressor recruitment by agonist-bound nuclear receptors. Vitam. Horm. 68, 123-143. doi: 10.1016/S0083-6729(04)68004-6

Williams, C. C., Allison, J. G., Vidal, G. A., Burow, M. E., Beckman, B. S., Marrero, L., et al. (2004). The ERBB4/HER4 receptor tyrosine kinase regulates gene expression by functioning as a STAT5A nuclear chaperone. J. Cell Biol. 167, 469-478. doi: 10.1083/jcb.200403155

Xiao, R., Sun, D., Ayers, S., Xi, Y., Li, W., Baxter, J. D., et al. (2012). Research resource: the estrogen receptor alpha cistrome defined by DamIP. Mol. Endocrinol. 26, 349-357. doi: 10.1210/me.2011-1080

Xu, J., Liao, L., Ning, G., Yoshida-Komiya, H., Deng, C., and O'malley, B. W. (2000). The steroid receptor coactivator SRC-3 (p/CIP/RAC3/AIB1/ACTR/TRAM-1) is required for normal growth, puberty, female reproductive function, and mammary gland development. Proc. Natl. Acad. Sci. U.S.A. 97, 6379-6384. doi: $10.1073 /$ pnas. 120166297 
Xu, J., Qiu, Y., Demayo, F. J., Tsai, S. Y., Tsai, M. J., and O'malley, B. W. (1998). Partial hormone resistance in mice with disruption of the steroid receptor coactivator-1 (SRC-1) gene. Science 279, 1922-1925.

Xu, X., Wagner, K. U., Larson, D., Weaver, Z., Li, C., Ried, T., et al. (1999). Conditional mutation of Brcal in mammary epithelial cells results in blunted ductal morphogenesis and tumour formation. Nat. Genet. 22, 37-43. doi: $10.1038 / 8743$

Yahata, T., Shao, W., Endoh, H., Hur, J., Coser, K. R., Sun, H., et al. (2001). Selective coactivation of estrogen-dependent transcription by CITED1 CBP/p300binding protein. Genes Dev. 15, 2598-2612. doi: 10.1101/gad.906301

Zhang, H., Singh, R. R., Talukder, A. H., and Kumar, R. (2006). Metastatic tumor antigen 3 is a direct corepressor of the Wnt4 pathway. Genes Dev. 20, 2943-2948. doi: 10.1101/gad.1461706

Zheng, L., Annab, L. A., Afshari, C. A., Lee, W. H., and Boyer, T. G. (2001). BRCA1 mediates ligand-independent transcriptional repression of the estrogen receptor. Proc. Natl. Acad. Sci. U.S.A. 98, 9587-9592. doi: 10.1073/pnas.171174298

Zhu, Y., Sullivan, L. L., Nair, S. S., Williams, C. C., Pandey, A. K., Marrero, L., et al. (2006). Coregulation of estrogen receptor by ERBB4/HER4 establishes a growth-promoting autocrine signal in breast tumor cells. Cancer Res. 66, 7991-7998. doi: 10.1158/0008-5472.CAN-05-4397
Zwijsen, R. M., Buckle, R. S., Hijmans, E. M., Loomans, C. J., and Bernards, R. (1998). Ligand-independent recruitment of steroid receptor coactivators to estrogen receptor by cyclin D1. Genes Dev. 12, 3488-3498.

Conflict of Interest Statement: The authors declare that the research was conducted in the absence of any commercial or financial relationships that could be construed as a potential conflict of interest.

Received: 15 May 2014; accepted: 21 July 2014; published online: 12 August 2014. Citation: Manavathi B, Samanthapudi VSK and Gajulapalli VNR (2014) Estrogen receptor coregulators and pioneer factors: the orchestrators of mammary gland cell fate and development. Front. Cell Dev. Biol. 2:34. doi: 10.3389/fcell.2014.00034

This article was submitted to Cellular Endocrinology, a section of the journal Frontiers in Cell and Developmental Biology.

Copyright (C) 2014 Manavathi, Samanthapudi and Gajulapalli. This is an openaccess article distributed under the terms of the Creative Commons Attribution License (CC BY). The use, distribution or reproduction in other forums is permitted, provided the original author(s) or licensor are credited and that the original publication in this journal is cited, in accordance with accepted academic practice. No use, distribution or reproduction is permitted which does not comply with these terms. 